\title{
Established breast cancer risk factors by clinically important tumour characteristics
}

\author{
M García-Closas*,', LA Brinton', J Lissowska ${ }^{2}$, N Chatterjee', B Peplonska ${ }^{3}$, WF Anderson', \\ N Szeszenia-Dąbrowska ${ }^{3}$, A Bardin-Mikolajczak ${ }^{2}$, W Zatonski ${ }^{2}$, A Blair', Z Kalaylioglu ${ }^{4}$, G Rymkiewicz ${ }^{5}$, \\ D Mazepa-Sikora ${ }^{5}$, R Kordek $^{6}$, S Lukaszek $^{7}$ and ME Sherman'
}

'Division of Cancer Epidemiology and Genetics, National Cancer Institute, National Institute of Health, 61 20 Executive Blvd. Room 7076, Rockville, MD 20852-7234, USA; '2 Department of Cancer Epidemiology and Prevention, Cancer Center and M Sklodowska-Curie Institute of Oncology, Warsaw, Poland; ${ }^{3}$ Nofer Institute of Occupational Medicine, Łódź, Poland; ${ }^{4}$ MS, Silver Spring, MD, USA; ${ }^{5}$ Department of Pathology, Cancer Center and M SklodowskaCurie Institute of Oncology, Warsaw, Poland; ${ }^{6}$ Department of Pathology, Medical University of Łódź, Łódź, Poland; ${ }^{7}$ Department of Clinical

Pathomorphology, Polish Mother's Memorial Hospital-Research Institute, Łódź, Poland

\begin{abstract}
Breast cancer is a morphologically and clinically heterogeneous disease; however, it is less clear how risk factors relate to tumour features. We evaluated risk factors by tumour characteristics (histopathologic type, grade, size, and nodal status) in a populationbased case-control of 2386 breast cancers and 2502 controls in Poland. Use of a novel extension of the polytomous logistic regression permitted simultaneous modelling of multiple tumour characteristics. Late age at first full-term birth was associated with increased risk of large $(>2 \mathrm{~cm})$ tumours (odds ratios (95\% confidence intervals) I.19 (1.07-1.33) for a 5-year increase in age), but not smaller tumours ( $P$ for heterogeneity adjusting for other tumour features $\left(P_{\text {het }}\right)=0.007$ ). On the other hand, multiparity was associated with reduced risk for small tumours $\left(0.76(0.68-0.86)\right.$ per additional birth; $\left.P_{\text {het }}=0.004\right)$. Consideration of all tumour characteristics simultaneously revealed that current or recent use of combined hormone replacement therapy was associated with risk of small $(2.29(1.66-3.15))$ and grade I $(3.36(2.22-5.08))$ tumours $\left(P_{\text {het }}=0.05\right.$ for size and 0.0008 for grade I vs 3$)$, rather than specific histopathologic types ( $P_{\text {het }}=0.63$ for ductal vs lobular). Finally, elevated body mass index was associated with larger tumour size among both pre- and postmenopausal women $\left(P_{\text {het }}=0.05\right.$ and $0.000 \mathrm{I}$, respectively). None of these relationships were explained by hormone receptor status of the tumours. In conclusion, these data support distinctive risk factor relationships by tumour characteristics of prognostic relevance. These findings might be useful in developing targeted prevention efforts.

British Journal of Cancer (2006) 95, 123-129. doi: I 0.1038/sj.bjc.6603207 www.bjcancer.com
\end{abstract}

Published online 6 June 2006

(c) 2006 Cancer Research UK

Keywords: breast cancer; epidemiology; aetiologic heterogeneity; histology

Breast cancers vary greatly in clinical behaviour, histopathologic appearance, and molecular alterations. In addition, age-specific incidence rates for breast cancer vary by histologic tumour type (Anderson et al, 2004a), stage, and grade (Anderson et al, 2005) and hormone receptor status (Yasui and Potter, 1999; Anderson et al, 2002), suggesting that breast cancers might be aetiologically distinct. Thus, demonstrating that specific epidemiologic risk factors differ by clinically important tumour characteristics may facilitate the development of targeted prevention efforts. However, most epidemiologic studies performed to date have treated breast cancer as a single disease with a common set of risk predictors.

Mounting albeit still limited evidence from epidemiological studies suggests that breast cancer predictors vary by histological type and hormone receptor status. Specifically, combined oestrogen and progestin hormone replacement therapy (HRT) (Li et al, 2000; Chen et al, 2002; Daling et al, 2002; Newcomb et al, 2002; Li et al, 2003; Newcomer et al, 2003), and possibly late age at first

*Correspondence: Dr M García-Closas; E-mail: montse@nih.gov Received 21 February 2006; revised 10 May 2006; accepted 10 May 2006; published online 6 June 2006 birth (LiVolsi et al, 1982; Ewertz and Duffy, 1988; Stalsberg et al, 1989) may be more strongly associated with lobular as compared to ductal carcinomas. Epidemiologic data also suggest that hormone-related risk factors vary by hormone receptor status (Althuis et al, 2004).

In this report, we evaluated heterogeneity of established breast cancer risk factors stratified by histopathological type, tumour grade, size and nodal status, in a large population-based casecontrol study in Poland. We used a novel statistical method to disentangle the independent effects of these correlated tumour features, as well as to adjust for hormone receptor status (Chatterjee, 2004).

\section{MATERIALS AND METHODS}

\section{Study population}

A population-based breast cancer case-control study was conducted in Poland between 2000 and 2003. Eligible cases were women residing in Warsaw or Łódź, 20-74 years of age, and recently diagnosed with either histologically or cytologically 
confirmed incident in situ or invasive breast cancer. Cases were recruited through a rapid identification system organized at five participating hospitals, which identified about $90 \%$ of eligible cases, and cancer registries. Eligible control subjects were residents of Warsaw and Łódź without a history of breast cancer at enrollment. The Polish Electronic System, a database with demographic information from all residents of Poland, was used to randomly select controls frequency matched to cases on city and age in 5-year categories.

A total of 2386 cases ( $79 \%$ of eligibles) and 2502 controls ( $69 \%$ of eligibles) agreed to participate in a personal interview regarding known and suspected risk factors for breast cancer. The main reasons of nonparticipation for cases and controls, respectively, were refusal (19 and 25\%) and unable to locate (2 and 6\%). Interviews were conducted a median of 6.8 weeks following diagnosis for cases, and 2.4 weeks following identification for controls. A signed informed consent to participate in the study was obtained from all participants in accordance with the National Cancer Institute and local Institutional Review Boards.

\section{Risk factor information}

Women were considered premenopausal if they reported having natural menstrual periods at the time of interview, postmenopausal if periods had stopped, and unclear menopausal status if HRT use had been started before the natural periods stopped. Women who reported having breastfed for 1 month or less were considered as having never breastfed. Women who had used oral contraceptives or oral HRT for 1 month or less were classified as nonusers. Users of oral HRT were further classified as current or recent users ( $<2$ years since last use) of combined (estrogen and progesterone) HRT, past users ( $\geqslant 2$ years) of combined HRT, and users of oestrogen or progesterone HRT alone. Body mass index (BMI) was calculated using current weight $(\mathrm{kg})$ divided by standing height $(\mathrm{m})$ squared as measured by a trained nurse. For 114 cases and 156 controls without measures of weight or height, BMI was calculated using self-reported information. Women were classified as non-drinkers if they reported having consumed 12 or fewer alcoholic drinks in their lifetime or they reported consuming less than one drink per month for 6 months without ever having had more than five drinks on any one occasion. Women were considered as having a history of benign breast disease if they reported having had a benign breast biopsy 1 year prior to either the diagnosis date (for cases) or the date of interview (for controls).

\section{Pathology information}

Information about diagnostic and treatment procedures was obtained from the medical records, and surgical pathology forms that were completed after clinical sign-out of cases. The surgical pathology form documented macroscopic (type and size of surgical specimens and location and size of masses) and microscopic (histopathologic diagnosis, grade, and status of axillary and other lymph nodes) features. Results for oestrogen receptor (ER) and progesterone receptor (PR) assays performed in Poland were obtained from medical records. In $91 \%$ of cases with receptor status information, assays were performed using immunohistochemistry, with biochemical methods used in the remainder.

A single US pathologist (MES) reviewed haematoxylin and eosin-stained slides to confirm case status and provide uniform histologic classification. Final diagnoses for 1958 (82\%) cases with tumour slides available were based on the pathology review by MES. Tumours were classified as ductal not otherwise specified (NOS) or lobular if they demonstrated a predominant histopathologic appearance; tumours containing mixed patterns were designated as mixed carcinomas. Carcinomas were classified as tubular or cribriform if the characteristic well-differentiated patterns together accounted for $90 \%$ of the tumour area. Tubular carcinomas and ductal carcinomas, NOS, grade 1 share morphologic and clinical features. Accordingly, we combined these types in some analyses. Studies have also suggested that low-grade ductal or tubular carcinomas are related to infiltrative lobular carcinomas, with the former being the most highly differentiated and the later the most undifferentiated extreme, a view that is supported by the observation of patterns of low-grade ductal and lobular carcinomas together in tubulo-lobular carcinomas (Fisher et al, 1977; Eusebi et al, 1979; Green et al, 1997). Thus, all of these types have also been combined in some analyses. Grading was performed according to Elston criteria (Elston and Ellis, 1998), with the modification that mitotic rate was estimated.

For the remaining 428 cases without slides available for review, the diagnosis in Poland was considered the final diagnosis. The percent agreement between MES and Poland for invasive diagnosis was $80 \%$ for ductal NOS, $68 \%$ for lobular, and $18 \%$ for mixed carcinomas. The disagreement was mainly explained by reclassification of mixed type tumours as ductals or lobulars.

\section{Statistical analysis}

Logistic regression was used to estimate adjusted odds ratios (ORs) and associated 95\% confidence intervals (CI) from models that included all risk factors simultaneously. Models included continuous terms for age at menarche, number of full-term births, age at first full-term birth, age at menopause and BMI, and dummy variables for education levels, nulliparity, oral HRT use (never user, current or recent use of combined HRT, past use of combined HRT, use of other HRT), family history, history of a benign biopsy, ever had a screening mammography and menopausal status (premenopausal, postmenopausal, and unclear), current age in 5year categories and study site. Because the association between BMI and breast cancer risk is known to differ by menopausal status, our models included separate terms for pre-and postmenopausal women. Estimation of ORs for different categories of variables considered as continuous indicated that the log-linear assumption was reasonable. Standard polytomous logistic regression was used to estimate ORs and 95\% CI for different tumour types. Heterogeneity between risk factor ORs for different tumour types was assessed using logistic regression analyses restricted to cases (case-only analyses). An extension of the polytomous logistic regression model was used to evaluate heterogeneity in risk factor ORs by multiple tumour characteristics simultaneously (Chatterjee, 2004). This method allowed us to evaluate which of several correlated tumour features, that is, histopathologic type, grade, size and nodal status, was most important in determining risk factor associations. Oestrogen receptor and PR status were also included as potential confounders. These analyses included cases diagnosed with major histological subtypes (ductal carcinomas, NOS; tubular carcinomas (classified as grade 1 ductal carcinoma, NOS); lobular; and mixed carcinomas; total $N=1964)$. Odds ratios (95\% CI) and corresponding $P$-values $\left(P_{\text {het }}\right)$ reported from these analyses measure the association between tumour characteristics and risk factors, similar to case-only analyses.

\section{RESULTS}

\section{Characteristics of study population}

About two-thirds of women were recruited in Warsaw and onethird in Łódź, with a mean age $( \pm$ s.d.) of $56( \pm 10)$ years. Distribution of characteristics for cases and controls were consistent with most established risk factors (Table 1). Use of oral contraceptives or HRT, alcohol consumption, and mammographic screening were relatively uncommon in this population. 
Table I Characteristics of the study population in the Polish Breast Cancer Study

\begin{tabular}{|c|c|c|}
\hline & Cases & Controls \\
\hline Study characteristic & $N=2386$ & $N=2502$ \\
\hline Age in years (mean \pm s.d.) & $55.8 \pm 10.0$ & $55.9 \pm 10.1$ \\
\hline Study site (\% Warsaw) & 65 & $\overline{63}$ \\
\hline Education level (\% college degree) & 25 & 15 \\
\hline Marital status (\% married) & 62 & 63 \\
\hline Age at menarche in years (mean \pm s.d.) & $13.5 \pm 1.7$ & $13.7 \pm 1.7$ \\
\hline Parity (\% parous) & $8 \overline{6}$ & $8 \overline{9}$ \\
\hline Number of full-term births (mean \pm s.d.) & $1.7 \pm 0.8$ & $1.9 \pm 0.8$ \\
\hline Age at first full-term birth (mean + s.d.) & $24.5+4.6$ & $23.6+4.2$ \\
\hline $\begin{array}{l}\text { Breastfeeding among women with live births } \\
\text { (\% ever) }\end{array}$ & $7 \overline{8}$ & $8 \overline{1}$ \\
\hline Oral contraceptive use (\% ever) & 12 & 10 \\
\hline Dpausal) & 75 & 70 \\
\hline $\begin{array}{l}\text { Type of menopause among postmenopausal } \\
\text { women (\% natural) }\end{array}$ & 77 & 84 \\
\hline Age at menopause (mean \pm s.d.) & $49.6 \pm 4.6$ & $49.2 \pm 5.0$ \\
\hline \multicolumn{3}{|l|}{$\begin{array}{l}\text { Use of oral HRT among postmenopausal } \\
\text { women (\% ever) }\end{array}$} \\
\hline Never & 77 & 83 \\
\hline $\begin{array}{l}\text { Current use of combined therapy } \\
\text { ( }<6 \text { months) }\end{array}$ & 7 & 4 \\
\hline $\begin{array}{l}\text { Recent use of combined therapy } \\
\text { ( } 6 \text { months }-<2 \text { years })\end{array}$ & 4 & 2 \\
\hline $\begin{array}{l}\text { Past use of combined therapy } \\
\text { (last use } 2 \text { or more years ago) }\end{array}$ & 4 & 5 \\
\hline Ever used $E$ or $P$ alone & 7 & 7 \\
\hline $\begin{array}{l}\text { Duration of combined HRT among current/recent } \\
\text { users (mean } \pm \text { s.d.) }\end{array}$ & $11.1 \pm 12.5$ & $9.7 \pm 10.7$ \\
\hline Current BMI among premenopausal (mean \pm s.d.) & $25.4 \pm 4.9$ & $26.4 \pm 5.1$ \\
\hline Current BMI among postmenopausal (mean \pm s.d.) & $27.9 \pm 5.4$ & $28.6 \pm 5.4$ \\
\hline Alcohol consumption (\% ever) & $3 \overline{3}$ & $3 \overline{2}$ \\
\hline $\begin{array}{l}\text { Family history of breast cancer in first-degree } \\
\text { relatives (\%) }\end{array}$ & 10 & 6 \\
\hline Prior benign breast bipospy (\%) & 10 & 6 \\
\hline Ever had a screening mammogram (\%) & 62 & 54 \\
\hline
\end{tabular}

$\mathrm{BMI}=$ body mass index; HRT = hormone replacement therapy

Approximately $94 \%$ of all cases in the study had a tumour with an invasive component, with ductal carcinomas, NOS, accounting for $58 \%$ of invasive cases, lobular carcinoma for $16 \%$, and mixed carcinoma for $12 \%$ (Table 2). Lobular and mixed carcinomas were better differentiated than ductal carcinomas, NOS, whereas the distributions of tumour size and axillary lymph node metastases were similar across these tumour types (Table 3). Among ductal carcinomas, NOS, $59 \%$ were ER positive and $50 \%$ were $\mathrm{PR}$ positive; percentages for receptor detection were higher among lobular, mixed, tubular, and tubulo-lobular carcinomas. Analyses for heterogeneity between risk factors in the remainder of the manuscript was restricted to tumours with known invasive component $(N=2144)$.

\section{Predictors of invasive breast cancer risk by tumour histology}

Overall, breast cancer risk was directly associated with higher level of education, late age at first full-term birth, late age at menopause, current or recent use of combined HRT, family history of breast cancer and prior benign breast biopsy (Supplementary Table 4 online). On the other hand, breast cancer risk was inversely associated with late age at menarche, multiparity, and high BMI in pre-menopausal women (Supplementary Table 4 online). Among postmenopausal women, BMI was not associated with overall breast cancer risk. Oral contraceptive use and alcohol consumption were uncommon and unrelated to overall risk (data not shown); these factors were therefore not further considered.
Table 2 Histological types of breast cancer tumours in the Polish Breast Cancer Study $(N=2386)$

\begin{tabular}{|c|c|c|}
\hline & $\mathbf{N}$ & $\%$ \\
\hline \multicolumn{3}{|l|}{ Invasiveness } \\
\hline In situ & 135 & 6 \\
\hline Invasive component & 2144 & 94 \\
\hline Other & 11 & 0.5 \\
\hline Unknown & 96 & a \\
\hline \multicolumn{3}{|c|}{ Tumours with invasive component ${ }^{b}$} \\
\hline Ductal NOS & $|25|$ & 58 \\
\hline Lobular & 341 & 16 \\
\hline Mixed & 252 & 12 \\
\hline Tubular & 119 & 6 \\
\hline Tubulobular & 50 & 2 \\
\hline Medullary & 16 & I \\
\hline Papillary & 7 & 0.3 \\
\hline Mucinous & 20 & 1 \\
\hline Other primary carcinoma & 83 & 4 \\
\hline Other malignant tumour & 3 & 0.1 \\
\hline
\end{tabular}

${ }^{a}$ Cases with cytological but no histological confirmation. ${ }^{\mathrm{b}}$ Two cases had missing information. ${ }^{\mathrm{N} O S}=$ not otherwise specified.

Most predictors of risk were similar across histologic types, with the exception of current or recent use of combined HRT, which was associated with a greater risk for lobular and tubular as compared to ductal carcinomas, NOS (Figure 1; Supplementary Table 4 online). Current or recent use of combined HRT was also associated with an increased risk of tubulo-lobular carcinoma $(N=50$; ORs $(95 \% \mathrm{CI})$ of $1.85(0.67-5.09))$, although the precision of the estimate was limited by small numbers. Risk factor associations were similar for mixed and ductal carcinomas, NOS (Figure 1; Supplementary Table 4 online).

\section{Invasive breast cancer risk by tumour grade, size, and nodal status}

Differences in risk factors by tumour grade, size, and nodal status were evaluated for the major histological types (ductal NOS, tubular, lobular, and mixed tumours). For these analyses, tubular tumours were included with ductal carcinomas, NOS, grade 1 since they are a grade 1 ductal variant with similar morphological and clinical features.

Delayed age at first full-term birth was associated with increased risk for tumours that were large $(>2 \mathrm{~cm})(\mathrm{OR}(95 \% \mathrm{CI})=1.19$ $(1.07-1.33))$ or with positive nodes $(1.12(1.08-1.35))$. In contrast, the reduced breast cancer risk associated with multiparity was strongest for carcinomas that were small $(\leqslant 2 \mathrm{~cm})(0.76(0.68-$ $0.86)$ ) or node negative $(0.82(0.73-0.91))$ (Figure 2; Supplementary Table 6 online). Increased breast cancer risk associated with current or recent use of combined HRT was limited to low-grade carcinomas $(3.36(2.22-5.08))$ and tumours of small size (2.29 (1.66-315)) (Figure 2; Supplementary Tables 5 and 6 online). For the combined group including grade 1 ductal NOS/tubular, lobular, and tubulo-lobular carcinomas $(N=628)$, HRT use was associated with an OR (95\% CI) of 2.77 (1.96-3.91).

Elevated BMI in pre-menopausal women was associated with reduced risks for tumours that were small or node negative. Elevated BMI in postmenopausal women was not associated with overall breast cancer risk; however, data suggested an association with decreased risk of small or node negative tumours, and a small increased risk of larger or node positive tumours (Figure 2; Supplementary Table 6 online). Additional risk factor data are shown as supplementary data (Supplementary Tables 5 and 6 online). 
Table 3 Characteristics of different histological types of invasive breast cancer tumours in the Polish Breast Cancer Study

\begin{tabular}{|c|c|c|c|c|c|c|c|c|c|c|}
\hline & \multicolumn{2}{|c|}{$\begin{array}{l}\text { Ductal NOS }^{a} \\
\qquad N=|25|\end{array}$} & \multicolumn{2}{|c|}{$\begin{array}{l}\text { Lobular } \\
N=342\end{array}$} & \multicolumn{2}{|c|}{$\begin{array}{c}\text { Mixed } \\
N=252\end{array}$} & \multicolumn{2}{|c|}{$\begin{array}{l}\text { Tubular } \\
N=119\end{array}$} & \multicolumn{2}{|c|}{$\begin{array}{l}\text { Tubulo-lobular } \\
\qquad \mathbf{N}=\mathbf{5 0}\end{array}$} \\
\hline & $\mathbf{N}$ & $\%$ & $N$ & $\%$ & $\mathbf{N}$ & $\%$ & $\mathbf{N}$ & $\%$ & $\mathbf{N}$ & $\%$ \\
\hline \multicolumn{11}{|l|}{ Grade } \\
\hline I (well differentiated) & 121 & 11 & 60 & 19 & 40 & 17 & 112 & 100 & 33 & 66 \\
\hline 2 (moderately differentiated) & 591 & 51 & 228 & 74 & 160 & 66 & 0 & & 17 & 34 \\
\hline 3 (poorly differentiated) & 437 & 38 & 22 & 7 & 41 & 17 & 0 & & 0 & 0 \\
\hline \multicolumn{11}{|l|}{$\mathrm{TI}: \leqslant 2.0$} \\
\hline Tla: $\leqslant 0.5$ & 13 & I & 2 & I & I & 0 & 11 & 9 & I & 2 \\
\hline TIb: $>0.5-\leqslant 1.0$ & 116 & 10 & 34 & 11 & 27 & 11 & 37 & 31 & 7 & 14 \\
\hline TIc: $>1.0-\leqslant 2.0$ & 466 & 41 & 127 & 41 & 101 & 43 & 53 & 45 & 34 & 68 \\
\hline $\mathrm{T} 2:>2-\leqslant 5$ & 479 & 43 & 133 & 42 & 99 & 42 & 7 & 6 & 8 & 16 \\
\hline $\mathrm{T} 3:>5$ & 52 & 5 & 17 & 5 & 9 & 4 & 11 & 9 & 0 & 0 \\
\hline Unknown & 125 & & 29 & & 15 & & 0 & & & \\
\hline Unknown & 112 & & 29 & & 17 & & 14 & & & \\
\hline \multicolumn{11}{|l|}{ ER status } \\
\hline Negative & 398 & 41 & 56 & 20 & 59 & 30 & 10 & 12 & 4 & 10 \\
\hline Positive & 576 & 59 & 224 & 80 & 139 & 70 & 76 & 88 & 35 & 90 \\
\hline Unknown & 277 & & 62 & & 54 & & 33 & & | | & \\
\hline \multicolumn{11}{|l|}{$P R$ status } \\
\hline Negative & 483 & 50 & 107 & 38 & 66 & 33 & 27 & 32 & 7 & 18 \\
\hline Positive & 487 & 50 & 173 & 62 & 132 & 67 & 58 & 68 & 32 & 82 \\
\hline Unknown & 281 & & 62 & & 54 & & 34 & & |1 & \\
\hline Age at diagnosis (mean \pm s.d.) & 55.2 & \pm 10.4 & 57.0 & \pm 9.3 & 56.8 & \pm 10.0 & 55.7 & \pm 8.1 & 53.8 & \pm 8.6 \\
\hline
\end{tabular}

${ }^{a} \mathrm{NOS}=$ not otherwise specified.

\section{Simultaneous analysis of tumour characteristics}

In this section, we evaluate the association between predictors of breast cancer risk and different tumour characteristics simultaneously using a novel extension of polytomous logistic regression to account for multiple disease outcomes (Chatterjee, 2004). Odds ratios (95\% CI) from these analyses and their corresponding $P$-values ( $P_{\text {het }}$; shown in Supplementary Tables 5 and 6 online) measure the association between tumour characteristics and risk factors, similar to case-only analyses.

Late age at first full-term birth and multiparity were associated with larger tumour size: OR $(95 \%$ CI $)$ for size $>2 \mathrm{~cm} v s$ $\leqslant 2 \mathrm{~cm}=1.23(1.06-1.44), P_{\text {het }}=0.007$ for 5 -year increase in age at first birth; and $1.30(1.09-1.55), P_{\text {het }}=0.004$ for each additional full-term birth. However, associations between these risk factors and nodal status found in the standard polytomous logistic regression models were no longer significant in models considering multiple tumour characteristics simultaneously (Supplementary Tables 5 and 6 online).

Recent or current use of combined HRT was significantly related to low tumour grade $\left(0.38(0.23-0.65), P_{\text {het }}=0.0003\right.$, and 0.29 (0.14-0.60), $P_{\text {het }}=0.0008$ for grades 2 and 3 compared to grade 1 , respectively), and smaller tumour size $(0.60 \quad(0.36-0.99)$, $P_{\text {het }}=0.05$ for tumours $>2 \mathrm{~cm} v s \leqslant 2 \mathrm{~cm}$ ), but the association with lobular type suggested in the standard logisitic analyses (Figure 1) was no longer significant $\left(1.14(0.66-2.00), P_{\text {het }}=0.63\right.$ for lobular $v s$ ductal tumours). This model indicated that HRT use is related to tumour grade, independent of the histological type. Indeed, stratification of lobular tumours by grade $1(N=60)$ and grades 2 or $3(N=250)$ indicated a stronger increase in breast cancer risk for grade $1(3.62(1.52-8.63)) v s$ grades 2 or $3(2.18$ $(1.30-3.65)), P_{\text {het }}=0.12$.
Elevated BMI in pre- and postmenopausal women was associated with larger tumour size $\left(1.28(1.00-1.64), P_{\text {het }}=0.05\right.$; $1.30(1.14-1.49), P_{\text {het }}=0.0001$, respectively); however, the association with nodal status was present for pre-menopausal women $\left(1.28(1.00-1.62) P_{\text {het }}=0.04\right)$ but not for postmenopausal women $\left(1.04(0.92-1.19), P_{\text {het }}=0.51\right)$.

\section{DISCUSSION}

Analysis of data from this large population-based case-control study provides convincing evidence that breast cancer risk factors differ by clinically important tumour features, including histopathological type, grade, size, and nodal status. Thus, exposures that influence the risk of developing breast cancer might also affect the biology and clinical behaviour of the tumours that arise. These findings parallel data suggesting that molecular profiles of breast cancers are generally fixed at inception and represent important determinants of clinical behavior (Lacroix et al, 2004). Accordingly, understanding relationships between risk factors for breast cancer and tumour characteristics could have implications for screening and prevention.

Similar to a previous case-control study (Wohlfahrt et al, 1999), we found that delayed age at first full-term birth was associated with increased risk of tumours that were large or node positive, whereas multiparity was associated with reduced risk for small tumours. Furthermore, analyses using a novel statistical method, which considered all tumour characteristics simultaneously, indicated that late age at first full-term birth and multiparity were more strongly related to larger tumour size than nodal invasion. Thus, these reproductive factors might act primarily to enhance tumour growth rate or delay detection. Either explanation would 


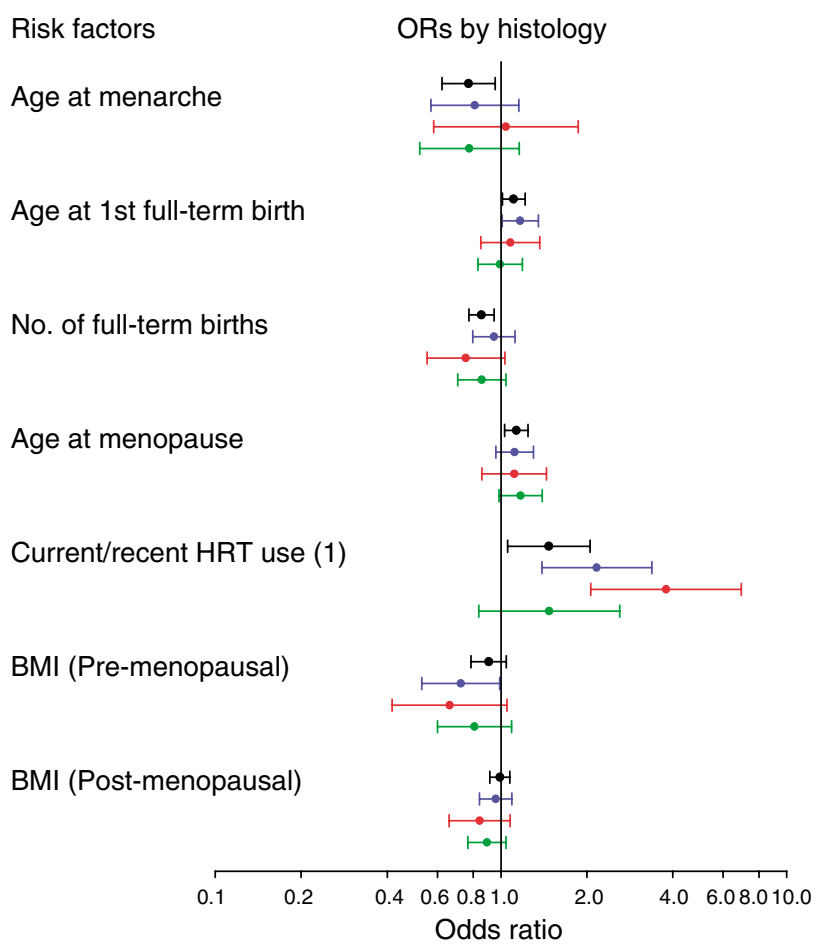

Figure I Predictors of invasive breast cancer risk in the Polish Breast Cancer Study by histological subtypes. Odds ratios $(95 \% \mathrm{Cl})$ for ductal carcinomas, $\operatorname{NOS}(N=1,25 \mathrm{I})$ are shown in black, for lobular carcinomas $(N=342)$ in blue, for tubular carcinomas $(N=119)$ in red, and for mixed carcinoma $(N=252)$ in green. Numbers in brackets denote statistically significant heterogeneity of ORs for lobular, tubular, and mixed compared to ductal carcinomas, NOS, respectively, based on standard polytomous logistic regression among cases: (I) 0.13, 0.002, and 0.98. Analyses are adjusted for age, study site, menopausal status, education level, family history, prior benign breast biopsy, screening mammogram, and all other factors shown in the figure. Comparison groups are 5-year increases for ages at menarche, first full-term birth, and menopause; each additional birth for number of full-term births; never HRT users for current or recent use of combined HRT; 5 unit increases for BMI.

favour implementing improved prevention efforts for these women. Although the mechanisms responsible for the associations of delayed age at first birth with poor prognostic features are unknown, continuous exposure to cyclic hormones uninterrupted by the dramatic differentiation and remodelling effects of pregnancy on breast tissue might play an important role. In contrast to some previous reports (LiVolsi et al, 1982; Ewertz and Duffy, 1988; Stalsberg et al, 1989), we and others (Morrison, 1976; Wohlfahrt et al, 1999) did not find that late age at first full-term birth was more strongly associated with lobular as compared with ductal carcinoma, NOS.

As previously reported, we found that HRT use was more strongly related to lobular (Gapstur et al, 1999; Li et al, 2000; Chen et al, 2002; Daling et al, 2002; Newcomb et al, 2002; Li et al, 2003; Newcomer et al, 2003) and tubular (Manjer et al, 2001) carcinomas than to other histopathologic types. In addition, we observed a stronger association between HRT use and risk for grade 1 ductal carcinomas, NOS, and tubulo-lobular carcinomas. This observation is consistent with the hypothesis that low-grade ductal or tubular and lobular carcinomas are aetiologically related and may represent the morphologic extremes of tumours (with the former being the most highly differentiated and the later the most undifferentiated extremes) that share a common carcinogenic pathway (Fisher et al, 1977; Eusebi et al, 1979; Green et al, 1997).

This report and others have found that combined HRT use is also associated with low grade or small tumours (Collaborative
Group on Hormonal Factors in Breast Cancer, 1997; Gapstur et al, 1999; Li et al, 2000; Manjer et al, 2001). Consideration of all tumour characteristics simultaneously in our analyses indicated that HRT use is primarily associated with tumour grade and to a lesser extent, with tumour size, whereas associations with histopathologic type or nodal status were not significant. It is possible that these findings reflect a detection bias associated with increased screening among HRT users; however, we found similar associations among screened and unscreened women (data not shown). In addition, it is known that HRT increases breast density, which decreases the sensitivity of mammography, and that mammography is insensitive in detecting lobular carcinomas. From a public health perspective, it is reassuring that the excess breast cancer risk associated with HRT use is related mainly to tumours with good prognostic features.

Findings from this case-control study provide support for an association between obesity and later stage at diagnosis, as it has been reported in most previous studies, mostly case-series (Daniell, 1988; Ingram et al, 1989; Verreault et al, 1989; Reeves et al, 1996; Jones et al, 1997; Hall et al, 1999; Cui et al, 2002), with a few exceptions (Donegan et al, 1978; Howson et al, 1986). In addition, consideration of all tumour characteristics simultaneously, suggested that obesity is primarily associated with larger tumour size rather than nodal status, particularly among postmenopausal women. Case-control analyses indicated that the association between obesity and larger tumour size in premenopausal women reflects a protection of obesity against small but not larger tumours, as it has been previously reported (Hall et al, 1999). This finding could reflect failed detection of smaller tumours by self or medical examination since tumours are more difficult to palpate in obese women. Among postmenopausal women only, high BMI was also associated with a small increase in risk for large tumours, which is consistent with growth enhancement due to higher levels of circulating hormones among obese than non-obese postmenopausal women. Previous studies have suggested that BMI is associated with hormone receptor-positive tumours which could confound the observed association with tumour size (Althuis et al, 2004). However, in our data, associations between BMI and tumour size were independent of hormone receptor status.

It has been suggested that tumours with poor prognostic features (i.e. high grade, large size, node positive, ER negative) differ aetiologically (Mueller, 1988; Anderson et al, 2004b; Li et al, 2005). Our data support this notion, challenging the view that tumour aggressiveness results entirely from stochastic molecular events that occur over time (Hellman and Harris, 2000). It is unclear whether risk factors directly affect prognosis, indirectly affect outcomes by influencing tumour characteristics at presentation or are unrelated to the clinical course.

Strengths of our study include large sample size, high participation rates, and standardised histopathologic assessment by an independent pathology review. In addition, we considered different tumour characteristics simultaneously using a novel statistical method (Chatterjee, 2004) which allowed us to evaluate the independent association of these characteristics, and adjust for hormone receptor status of the tumour. Although this study population had higher percentage of tumours with adverse prognostic features than those observed in other Western populations, most known breast cancer risk factors were present in similar magnitude as previously reported, indicating that our findings should be generalisable to other populations.

In summary, this population-based study provides evidence that breast cancer risk factors are associated with clinically important tumour characteristics, suggesting that aetiological factors may affect the biological behaviour of breast cancers. In addition, these data suggest that postmenopausal women who are nulliparous have later ages at first birth and are obese might benefit from more frequent screening. 


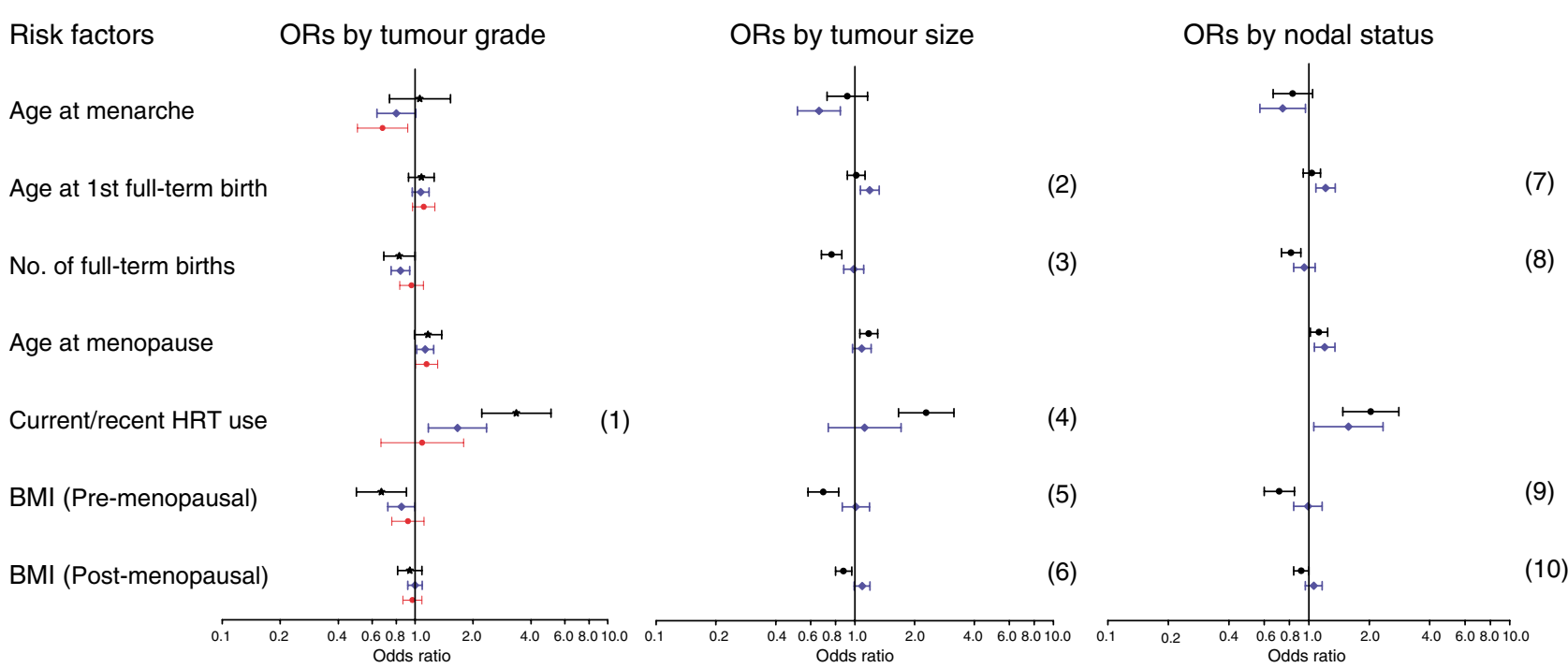

Figure 2 Predictors of invasive breast cancer (ductal carcinomas, NOS, tubular, lobular, and mixed types) in the Polish Breast Cancer Study by tumour grade, size, and nodal status. Odds ratio $(95 \% \mathrm{Cl})$ for grade I $(N=333)$, small $(\leqslant 2 \mathrm{~cm}, N=988)$, or node negative $(N=1084)$ tumours are shown in black; for grade $2(N=979)$, large $(>2 \mathrm{~cm}, N=796)$, or node positive $(N=708)$ are shown in blue; and for grade $3(N=500)$ are shown in red. Numbers in brackets denote statistically significant heterogeneity of ORs based on standard polytomous logistic regression among cases: (I) $0.00 \mathrm{I}$ and 0.00008 for grades 2 and 3 compared to grade I tumours, respectively; (2) 0.02, (3) 0.0019 , (4) 0.001 , (5) 0.0006, and (6) 0.0005 for small ( $\leqslant 2 \mathrm{~cm}$ ) compared to large $(>2 \mathrm{~cm}$ ) tumours; and (7) 0.02, (8) 0.006, (9) 0.002, and (10) 0.02 for node positive compared to node negative tumours. Analyses are adjusted for age, study site, menopausal status, education level, family history, prior benign breast biopsy, screening mammogram, and all other factors shown in the figure. Comparison groups are 5-year increases for ages at menarche, first full-term birth, menopause; each additional birth for number of full-term births; never HRT users for current or recent use of combined HRT; 5 unit increases for BMI.

\section{ACKNOWLEDGEMENTS}

We thank Anita Soni, and Elena Adrianza, (Westat, Rockville, MD) for their work on study management; Pei Chao (IMS, Silver Spring, MD) for her work on data and sample management; physicians, pathologists, and nurses from participating centers in Poland as well as interviewers and study participants for their efforts during field work. This research was supported by the Intramural Research Program of the National Cancer Institute, USA.

\section{Participating centers in Poland}

Cancer Center and M. Skodowska-Curie Institute of Oncology in Warsaw: Departments of Epidemiology (Coordinating center: Dr Jolanta Lissowska, Mrs Alicja Bardin-Mikolajczak, Dr Witold Zatonski), Breast Cancer Treatment and Reconstruction (Drs Edward Towpik and Jerzy Giermek), Departments of Surgical Oncology (Dr Pawel Kukawski), Pathology (Drs Grzegorz Rymkiewicz, Marcin Ligaj, Joanna Barańska, Agnieszka Turowicz, Włodzimierz Olszewski).

\section{REFERENCES}

Althuis MD, Fergenbaum JH, Garcia-Closas M, Brinton LA, Madigan MP, Sherman ME (2004) Etiology of hormone receptor-defined breast cancer: a systematic review of the literature. Cancer Epidemiol Biomarkers Prev 13: $1558-1568$

Anderson WF, Chatterjee N, Ershler WB, Brawley OW (2002) Estrogen receptor breast cancer phenotypes in the Surveillance, Epidemiology, and End Results database. Breast Cancer Res Treat 76: 27-36

Anderson WF, Chu KC, Chang S, Sherman ME (2004a) Comparison of age-specific incidence rate patterns for different histopathologic types of breast carcinoma. Cancer Epidemiol Biomarkers Prev 13: $1128-1135$

Anderson WF, Chu KC, Devesa SS (2004b) Distinct incidence patterns among in situ and invasive breast carcinomas,with possible etiologic implications. Breast Cancer Res Treat 88: 149-159
Polish Oncological Foundation in Warsaw:, Pathology (Drs Dorota Mazepa-Sikora, Włodzimierz Olszewski).

Nofer Institute of Occupational Medicine in Łódź (Drs Neonila Szeszenia-Dąbrowska, Beata Peplonska).

Medical University in Łódź, Oncology Clinic (Drs Arkadiusz Jeziorski, Janusz Piekarski), and Pathology Department (Drs Radzislaw Kordek, Grazyna Pasz-Walczak, Robert Kubiak, Dorota Kupnicka, Boguslaw Olborski).

Community Copernicus Hospital in Łódź, Department of Surgical Oncology (Drs Zbigniew Morawiec and Mariusz Pawlak).

Polish Mother's Health Memorial Hospital in Łódź: Departments Surgical Oncology and Breast Diseases (Drs Marcin Faflik, Magdalena Baklinska, Marek Zadrozny, Boguslaw Westfal) and Clinical Pathomorphology (Drs Stanislaw Lukaszek, Andrzej Kulig).

Supplementary Information accompanies the paper on British Journal of Cancer website (http://www.nature.com/bjc)

Anderson WF, Jatoi I, Devesa SS (2005) Distinct breast cancer incidence and prognostic patterns in the NCI's SEER program: suggesting a possible link between etiology and outcome. Breast Cancer Res Treat 90: $127-137$

Chatterjee N (2004) A two-stage regression model for epidemiological studies with multivariate disease classification data. JASA 99: 127-138

Chen CL, Weiss NS, Newcomb P, Barlow W, White E (2002) Hormone replacement therapy in relation to breast cancer. JAMA 287: $734-741$

Collaborative Group on Hormonal Factors in Breast Cancer (1997) Breast cancer and hormone replacement therapy: collaborative reanalysis of data from 51 epidemiological studies of 52705 women with breast cancer and 108411 women without breast cancer. Lancet 350: $1047-1059$ 
Cui Y, Whiteman MK, Flaws JA, Langenberg P, Tkaczuk KH, Bush TL (2002) Body mass and stage of breast cancer at diagnosis. Int J Cancer 98: $279-283$

Daling JR, Malone KE, Doody DR, Voigt LF, Bernstein L, Coates RJ, Marchbanks PA, Norman SA, Weiss LK, Ursin G, Berlin JA, Burkman RT, Deapen D, Folger SG, McDonald JA, Simon MS, Strom BL, Wingo PA, Spirtas R (2002) Relation of regimens of combined hormone replacement therapy to lobular, ductal, and other histologic types of breast carcinoma. Cancer 95: 2455-2464

Daniell HW (1988) Increased lymph node metastases at mastectomy for breast cancer associated with host obesity, cigarette smoking, age, and large tumor size. Cancer 62: 429-435

Donegan WL, Hartz AJ, Rimm AA (1978) The association of body weight with recurrent cancer of the breast. Cancer 41: $1590-1594$

Elston CW, Ellis IO (1998) Assessment of histological grade. In The Breast, Elston CW, Ellis IO (eds) pp 356 -384. Edinburgh, New York: Churchill Livingstone

Eusebi V, Betts CM, Bussolati G (1979) Tubular carcinoma: a variant of secretory breast carcinoma. Histopathology 3: 407-419

Ewertz M, Duffy SW (1988) Risk of breast cancer in relation to reproductive factors in Denmark. Br J Cancer 58: $99-104$

Fisher ER, Gregorio RM, Redmond C, Fisher B (1977) Tubulolobular invasive breast cancer: a variant of lobular invasive cancer. Hum Pathol 8: $679-683$

Gapstur SM, Morrow M, Sellers TA (1999) Hormone replacement therapy and risk of breast cancer with a favorable histology: results of the Iowa Women's Health Study. JAMA 281: $2091-2097$

Green I, McCormick B, Cranor M, Rosen PP (1997) A comparative study of pure tubular and tubulolobular carcinoma of the breast. Am J Surg Pathol 21: 653-657

Hall HI, Coates RJ, Uhler RJ, Brinton LA, Gammon MD, Brogan D, Potischman N, Malone KE, Swanson CA (1999) Stage of breast cancer in relation to body mass index and bra cup size. Int $J$ Cancer 82: $23-27$

Hellman S, Harris JR (2000) Natural history of breast cancer. In Disease of the Breast, Harris JP, Lippman ME, Morrow M, Osborne CK (eds) pp 407-423. Philadelphia: Lippincott Williamns \& Wilkins

Howson CP, Kinne D, Wynder EL (1986) Body weight, serum cholesterol, and stage of primary breast cancer. Cancer 58: 2372-2381

Ingram D, Nottage E, Ng S, Sparrow L, Roberts A, Willcox D (1989) Obesity and breast disease. The role of the female sex hormones. Cancer 64: $1049-1053$

Jones BA, Kasi SV, Curnen MG, Owens PH, Dubrow R (1997) Severe obesity as an explanatory factor for the black/white difference in stage at diagnosis of breast cancer. Am J Epidemiol 146: 394-404
Lacroix M, Toillon RA, Leclercq G (2004) Stable 'portrait' of breast tumors during progression: data from biology, pathology and genetics. Endocr Relat Cancer 11: 497-522

Li CI, Malone KE, Porter PL, Weiss NS, Tang MT, Cushing-Haugen KL, Daling JR (2003) Relationship between long durations and different regimens of hormone therapy and risk of breast cancer. JAMA 289: 3254-3263

Li CI, Uribe DJ, Daling JR (2005) Clinical characteristics of different histologic types of breast cancer. Br J Cancer 93: 1046-1052

Li CI, Weiss NS, Stanford JL, Daling JR (2000) Hormone replacement therapy in relation to risk of lobular and ductal breast carcinoma in middle-aged women. Cancer 88: 2570-2577

LiVolsi VA, Kelsey JL, Fischer DB, Holford TR, Mostow ED, Goldenberg IS (1982) Effect of age at first childbirth on risk of developing specific histologic subtype of breast cancer. Cancer 49: 1937-1940

Manjer J, Malina J, Berglund G, Bondeson L, Garne JP, Janzon L (2001) Increased incidence of small and well-differentiated breast tumours in post-menopausal women following hormone-replacement therapy. Int $J$ Cancer 92: $919-922$

Morrison AS (1976) Histologic specificity of the effect of age at birth of first child on breast cancer risk. Int J Cancer 18: 723-726

Mueller CB (1988) Stage II breast cancer is not simply a late stage I. Surgery 104: $631-638$

Newcomb PA, Titus-Ernstoff L, Egan KM, Trentham-Dietz A, Baron JA, Storer BE, Willett WC, Stampfer MJ (2002) Postmenopausal estrogen and progestin use in relation to breast cancer risk. Cancer Epidemiol Biomarkers Prev 11: 593-600

Newcomer LM, Newcomb PA, Potter JD, Yasui Y, Trentham-Dietz A, Storer BE, Longnecker MP, Baron JA, Daling JR (2003) Postmenopausal hormone therapy and risk of breast cancer by histologic type (United States). Cancer Causes Control 14: 225-233

Reeves MJ, Newcomb PA, Remington PL, Marcus PM, MacKenzie WR (1996) Body mass and breast cancer. Relationship between method of detection and stage of disease. Cancer 77: $301-307$

Stalsberg H, Thomas DB, Noonan EA (1989) Histologic types of breast carcinoma in relation to international variation and breast cancer risk factors. WHO Collaborative Study of Neoplasia and Steroid Contraceptives. Int J Cancer 44: 399-409

Verreault R, Brisson J, Deschenes L, Naud F (1989) Body weight and prognostic indicators in breast cancer. Modifying effect of estrogen receptors. Am J Epidemiol 129: 260-268

Wohlfahrt J, Andersen PK, Mouridsen HT, Adami HO, Melbye M (1999) Reproductive history and stage of breast cancer. Am J Epidemiol 150: $1325-1330$

Yasui Y, Potter JD (1999) The shape of age-incidence curves of female breast cancer by hormone-receptor status. Cancer Causes Control 10: 431-437 